\title{
Microscopic Anterior Callosotomy for Management of Intractable Epilepsy (Al-Azhar Experience)
}

\author{
Alaa Rashad Ibrahim, Mohammed Attia \\ Neurosurgery Department, Faculty of Medicine, Al-Azhar University, Cairo, Egypt \\ Email: alaarashad81@yahoo.com, mohameddr594@gmail.com
}

How to cite this paper: Ibrahim, A.R. and Attia, M. (2021) Microscopic Anterior Callosotomy for Management of Intractable Epilepsy (Al-Azhar Experience). Open Journal of Modern Neurosurgery, 11, 180-193. https://doi.org/10.4236/ojmn.2021.113022

Received: May 22, 2021

Accepted: July 13, 2021

Published: July 16, 2021

Copyright $\odot 2021$ by author(s) and Scientific Research Publishing Inc. This work is licensed under the Creative Commons Attribution International License (CC BY 4.0).

http://creativecommons.org/licenses/by/4.0/ Open Access

\begin{abstract}
Background: Anterior Corpus Callosotomy is a palliative treatment for drug-resistant generalized or multifocal epilepsy patients where focus excision is not an option for management. Callosotomy prevents propagation of epileptic discharge from one cerebral hemisphere to the other. Objective: To describe Al-Azhar University Hospitals experience and clinical outcome of Anterior Corpus Callosotomy for management of drug-resistant generalized epilepsy patients as an inexpensive palliative method. Patients and Methods: In this study, there are 15 patients admitted to Neurosurgery Department in Al-Azhar University Hospitals with drug-resistant generalized epilepsy. These patients were not candidates for lesionectomy. They were managed by anterior two thirds Corpus Callosotomy between February 2017 and December 2019. They were followed at outpatient clinic for at least 14 months. Clinical outcome regarding seizure control was assessed using Engel classification. Results: All 15 patients in this study underwent anterior two thirds corpus callosotomy and followed for at least 14 months. The post-operative improvement of seizure frequency has been evaluated using Engel outcome scale with 12 patients $(80 \%)$ of the patients becoming Engel class II and 3 patients (20\%) becoming Engel class III. Only 3 patients (20\%) had minor transient postoperative complications; one patient (6.67\%) had contra-lateral lower limb heaviness Grade 4 which was transient, one patient $(6.67 \%)$ had contra-lateral lower limb Jacksonian focal fits and one patient (6.67\%) had behavioral changes for one month. Conclusion: Corpus callosotomy is a palliative procedure and inexpensive method for management of patients with intractable focal with generalization and generalized drug-resistant epilepsy who are not suitable for resective surgery and with good outcome.
\end{abstract}

\section{Keywords}

Drug-Resistant Epilepsy, Palliative Treatment, Corpus Callosotomy, Engel 


\section{Introduction}

The idea of surgical treatment for epilepsy is not new. However, widespread use and general acceptance of this treatment have only been achieved during the past three decades.

Corpus callosotomy may be indicated for uncontrolled generalized tonic-clonic seizures, atonic seizures, Lennox-Gastaut syndrome, and drop attacks. The purpose is to interfere with the propagation of seizures rather than with their initiation [1].

Recently corpus callosotomy is indicated for other types of epilepsy of different etiologies including drug resistant focal with generalization epilepsy without identifiable lesion and patients with multi-lesions that cannot be excised [2].

Corpus callosotomy can be performed in a complete or partial manner, depending on the results of preoperative investigation. After incomplete callosotomy, some patients may require re-operation to do complete callosotomy to achieve better control of drop attacks [1].

Anterior callosotomy means any corpus callosum section that spares the splenium and all or part of the isthmus, while complete callosotomy is any callosal section that involved the splenium [3].

It is accepted that corpus callosotomy is ineffective for temporal lobe epilepsy [4], as contra-lateral seizure spread in temporal lobe complex partial seizures may occur through interhemispheric connections other than the corpus callosum [5].

Patients most likely to be candidates for corpus callosotomy are those with symptomatic generalized epilepsy or frontal lobe epilepsy [5].

The risks associated with elective and functional improvement surgery are an important issue. Surgery for epilepsy is often considered for young and healthy patients. Prospective success has to be weighed against potential risks [1].

There are different classification systems used for evaluation of the outcome of epilepsy surgeries. The most popular scale is Engel classification system. All used seizure-outcome scales contain subjective components, such as "worthwhile improvement" or "significant reduction" [6].

The Engel classification system:

- Class I-No disabling seizures.

- Class II-Rare disabling seizures.

- Class III-Worthwhile improvement.

- Class IV-No worthwhile improvement [6].

There is controversy to use Engel classification in palliative procedures as it is designed to evaluate the outcome after surgical epileptogenic lesions resection [7]. As corpus callosotomy is a palliative treatment, there is controversy to use 
this classification for assessment of fits postoperative surgical outcome [8]. However, Engel classification is commonly used in clinical practice to evaluate outcome after callosotomy [7].

This study was done to describe Al-Azhar University Hospitals experience in doing callosotomy for cases with drug-resistant epilepsy who aren't candidates for lesionectomy, to show their clinical outcome and to show corpus callosotomy as an inexpensive palliative method.

\section{Material and Methods}

This is a retrospective series of 15 patients with age ranged from 6-year-old to age 40-year-old presented to Al-Azhar University Hospitals (Al-Hussien and Sayed Galal University Hospitals) between February 2017 and December 2019. These 15 patients were the whole number of patients presented to our hospitals during this period with the inclusion criteria of our study including history of disabling drug-resistant generalized epilepsy without discrete foci and were not candidates for focus resection. These patients were managed with Microscopic Anterior Corpus Callosotomy.

\section{Data Collection and Processing}

Data were collected and saved in summary sheets case by case. Hospital records and radiology films of the patients were electronically saved and customized to meet our specific needs.

The type of epilepsy and neuropsychological assessments were recorded as per the neurologist and the neurosurgeon's preoperative assessment.

The pre-operative investigations and assessment were electronically collected and saved.

The decision regarding the treatment of the patient with Corpus Callosotomy was taken after agreement of the all members of epilepsy team and so was done. All anesthetic and neurosurgical records were reviewed.

The statistics were made from a master table (Table 1) containing relevant history, clinical and radiological data extracted from the summary sheets and radiology films.

All percentages were approximated to two decimal places. Statistics were made by Microsoft office 2007.

This study was approved by the Scientific Committee in neurosurgery department, faculty of medicine for boys in Cairo, Al-Azhar University.

\section{Pre-Operative Evaluation}

For pre-surgical evaluation, all patients underwent clinical and neuropsychological evaluation, neuro-imaging (Magnetic Resonance (MR) Imaging), and repeated scalp EEG. When EEGs were recorded, sleep was induced by drugs and anticonvulsants were decreased in some cases when there was no risk of seizures occurrence. 
Table 1. Clinical picture, EEG findings, brain MRI findings and post-operative outcome of the study patients.

\begin{tabular}{|c|c|c|c|c|c|c|c|c|c|}
\hline \multirow[b]{2}{*}{$\begin{array}{c}\text { Case } \\
\text { Number }\end{array}$} & \multicolumn{5}{|c|}{ Clinical Findings } & \multirow[b]{2}{*}{$\begin{array}{c}\text { EEG } \\
\text { Finding }\end{array}$} & \multirow[b]{2}{*}{$\begin{array}{l}\text { Brain } \\
\text { MRI }\end{array}$} & \multirow[b]{2}{*}{$\begin{array}{c}\text { Post-op. } \\
\text { complications }\end{array}$} & \multirow[b]{2}{*}{$\begin{array}{c}\text { Outcome } \\
\text { (Engel Scale) }\end{array}$} \\
\hline & $\begin{array}{c}\text { Age } \\
\text { (years) }\end{array}$ & Sex & Mentality & Presentation & $\begin{array}{l}\text { Duration } \\
\text { of epilepsy } \\
\text { (years) }\end{array}$ & & & & \\
\hline 1 & 10 & Female & subnormal & $\begin{array}{l}\text { Lennox-Gastaut } \\
\text { syndrome }\end{array}$ & 4 & $\begin{array}{l}\text { Bifrontal } \\
\text { epileptic } \\
\text { activity }\end{array}$ & $\begin{array}{l}\text { Mild brain } \\
\text { atrophy }\end{array}$ & Non & II \\
\hline 2 & 29 & Male & normal & $\begin{array}{l}\text { Generalized } \\
\text { tonic-clonic fits }\end{array}$ & 20 & $\begin{array}{c}\text { Bilateral } \\
\text { frontotemporal } \\
\text { foci }\end{array}$ & $\begin{array}{c}\text { Mild brain } \\
\text { atrophy \& right } \\
\text { fronto-parietal } \\
\text { encephalomalacia }\end{array}$ & $\begin{array}{l}\text { lt. sided focal } \\
\text { fits for seconds } \\
\text { in } 2^{\text {nd }} \text { day }\end{array}$ & III \\
\hline 3 & 40 & Male & normal & $\begin{array}{c}\text { Generalized } \\
\text { tonic-clonic fits }\end{array}$ & 23 & $\begin{array}{l}\text { Left frontal } \\
\text { epileptic } \\
\text { discharge }\end{array}$ & NAD & Non & II \\
\hline 4 & 14 & Male & normal & $\begin{array}{c}\text { Generalized } \\
\text { tonic-clonic fits }\end{array}$ & $3 / 12$ & $\begin{array}{c}\text { Bilateral } \\
\text { centro-temporal } \\
\text { foci }\end{array}$ & $\begin{array}{l}\text { Mild brain } \\
\text { atrophy \& right } \\
\text { occipital cyst }\end{array}$ & Non & II \\
\hline 5 & 12 & Male & normal & $\begin{array}{l}\text { Generalized } \\
\text { tonic-clonic fits }\end{array}$ & 6 & $\begin{array}{l}\text { Bifrontal } \\
\text { epileptic } \\
\text { activity }\end{array}$ & NAD & Non & III \\
\hline 6 & 10 & Male & subnormal & $\begin{array}{c}\text { Generalized } \\
\text { tonic-clonic fits }\end{array}$ & 3 & $\begin{array}{l}\text { Multifocal } \\
\text { discharges }\end{array}$ & NAD & $\begin{array}{l}\text { Left lower } \\
\text { limb weakness } \\
\text { with power }\end{array}$ & II \\
\hline 7 & 16 & Female & normal & $\begin{array}{c}\text { Generalized } \\
\text { tonic-clonic fits }\end{array}$ & 2 & $\begin{array}{l}\text { Bifrontal } \\
\text { epileptic } \\
\text { activity }\end{array}$ & NAD & Non & III \\
\hline 8 & 10 & Male & subnormal & $\begin{array}{l}\text { Generalized } \\
\text { tonic-clonic fits }\end{array}$ & 2 & $\begin{array}{c}\text { Bilateral } \\
\text { generalized } \\
\text { discharges }\end{array}$ & $\begin{array}{l}\text { Mild brain } \\
\text { atrophy }\end{array}$ & $\begin{array}{l}1 \text { month } \\
\text { behavior } \\
\text { changes }\end{array}$ & II \\
\hline 9 & 11 & Male & normal & $\begin{array}{l}\text { Generalized } \\
\text { tonic-clonic fits }\end{array}$ & 4 & $\begin{array}{l}\text { Bifrontal } \\
\text { epileptic } \\
\text { activity }\end{array}$ & NAD & Non & II \\
\hline 10 & 15 & Male & normal & $\begin{array}{c}\text { Generalized } \\
\text { tonic-clonic fits }\end{array}$ & 7 & $\begin{array}{l}\text { Bilateral } \\
\text { generalized } \\
\text { discharges }\end{array}$ & NAD & Non & II \\
\hline 11 & 6 & Female & subnormal & $\begin{array}{l}\text { Generalized } \\
\text { tonic-clonic fits }\end{array}$ & 2 & $\begin{array}{c}\text { Bilateral } \\
\text { generalized } \\
\text { discharges }\end{array}$ & $\begin{array}{l}\text { Brain } \\
\text { atrophy }\end{array}$ & Non & II \\
\hline 12 & 8 & Male & normal & $\begin{array}{l}\text { Generalized } \\
\text { tonic-clonic fits, } \\
\text { atypical absence } \\
\text { and other } \\
\text { multiform } \\
\text { seizures }\end{array}$ & 3 & $\begin{array}{l}\text { Generalized } \\
\text { multifocal } \\
\text { discharges }\end{array}$ & NAD & Non & II \\
\hline 13 & 12 & Female & normal & $\begin{array}{l}\text { Generalized } \\
\text { tonic-clonic fits }\end{array}$ & 5 & $\begin{array}{c}\text { Bilateral } \\
\text { generalized } \\
\text { discharges }\end{array}$ & NAD & Non & II \\
\hline
\end{tabular}




\section{Continued}

\begin{tabular}{|c|c|c|c|c|c|c|c|c|c|}
\hline 14 & 8 & Male & normal & $\begin{array}{c}\text { Generalized } \\
\text { tonic-clonic fits }\end{array}$ & 3 & $\begin{array}{c}\text { Bilateral } \\
\text { generalized } \\
\text { discharges }\end{array}$ & NAD & Non & II \\
\hline 15 & 11 & Male & subnormal & $\begin{array}{c}\text { Generalized } \\
\text { tonic-clonic fits }\end{array}$ & 6 & $\begin{array}{c}\text { Bilateral } \\
\text { generalized } \\
\text { discharges }\end{array}$ & $\begin{array}{c}\text { Mild brain } \\
\text { atrophy }\end{array}$ & Non & II \\
\hline
\end{tabular}

We made sure of taking the informed consent from all patients included in this study before the procedure and assured that it included simple explanation of the procedure and possible complications with notification to its failure rates in some cases. Also detailed explanation for other possible alternative procedures can be done for these patients including Vagal Nerve Stimulation (VNS), their expenses and availability.

\section{The Surgical Technique}

The procedure was done for all study patients under general anesthesia with endo-tracheal intubation.

Prophylactic pre-operative antibiotics (cefotaxime 2 grams or as the patient's weight) were used for all cases and continued post-operatively $1.5 \mathrm{gm}$ every 8 hours (or as the patient's weight) till discharge from hospital.

Intra-operatively, loading anti-epileptics (phenytoin) doses according to the weight of the patients were given at the start of the procedure.

The patients used their regular pre-operative anti-epileptic medications with sip of water during the pre-operative period to avoid missing any doses of the anti-epileptics.

The patient was positioned supine. Head was mildly flexed and fixed with head holder and Mayfield Head supporter. Back was elevated above the level of the heart (Figure 1).

The skin of the scalp was shaved and sterilized. A curvilinear incision (usually 10 centimeter $(\mathrm{cm})$ was done which was $1 \mathrm{~cm}$ anterior to the coronal suture with two thirds of the incision length to the right side and one third to the left.

The bone flap was done by doing 4 burr holes; the first one was $3 \mathrm{~cm}$ right to midline and $2 \mathrm{~cm}$ behind the coronal suture, the second burr hole was $3 \mathrm{~cm}$ right to midline and $3 \mathrm{~cm}$ anterior to the coronal suture and the other two burr holes were parasagittal on the left side of midline and $5 \mathrm{~cm}$ apart. Then, the bone flap was freely elevated.

The dura was opened with the base on the sagittal sinus. Dural opening was done very cautiously to avoid injury of any draining veins.

The corpus callosum was then approached through the interhemispheric fissure with care to cingulate gyrus on both sides and terminal branches of the anterior cerebral arteries (calloso-marginal and pericallosal arteries).

The anterior two thirds of the corpus callosum were usually cut from the genu back to the parietal thinning. 


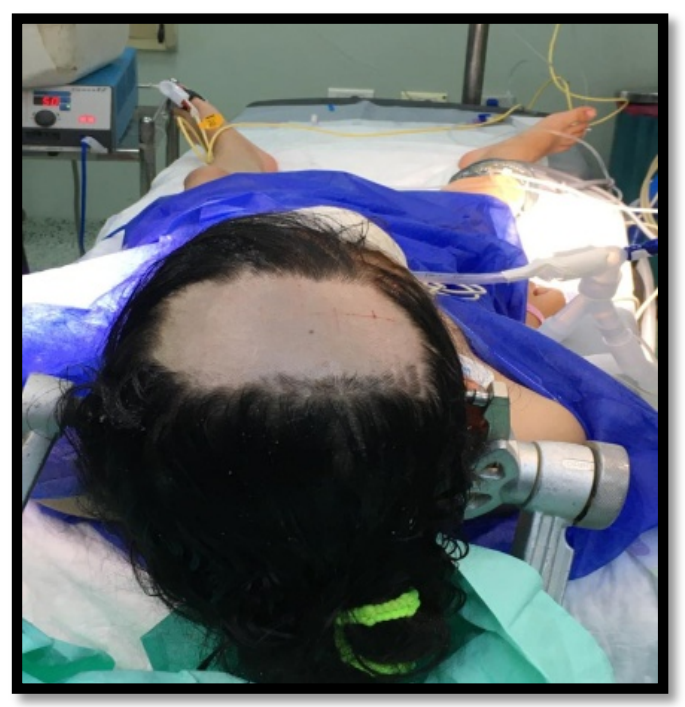

Figure 1. Intra-operative photo of one of the study patients showing the position of the patient and the planned incision for microscopic anterior corpus callosotomy.

Then, good hemostasis was done followed by saline irrigation, closure of the wound in layers and finally head dressing.

All patients were admitted to the ICU for the first day with continuation of pre-operative anti-epileptic medications (same doses and time). Then, the patients were shifted to the regular ward for another day then discharged to home except if there was any cause or surgical complications that needed longer stay in the hospital.

Follow up CT Brain scans were done on the second post-operative day to exclude any complications and to assess primarily the extent of callosotomy.

Follow up of the patients, assessment of post-operative outcome using Engel classification scale, and more assessment of callosotomy extent by Brain MRI were done during successive visits to outpatient clinic through the postoperative period which was at least for 14 months.

\section{Results}

This study is a retrospective study of 15 patients presented with drug-resistant generalized or multifocal epilepsy to Al-Azhar University Hospitals during the period from February 2017 till December 2019, underwent microscopic anterior corpus callosostmy and followed clinically for at least 14 months in outpatient clinics. Table 1 shows the clinical and radiological criteria of all patients of this study.

The study included 4 female patients (26.67\%) and 11 male patients $(73.33 \%)$ with age ranging from 6 years old to 40 years old with mean age of 14.13 years.

Patients of the current study suffered from seizures before surgery for different periods ranging from 3 months up to 23 years with mean time of 6.016 years. There was one patient that suffered from refractory epilepsy for only 3 months and there were two cases that suffered for 20 and 23 years. 
The semiology of seizures in patients of the current study was generalized tonic-clonic in 13 patients $(86.67 \%)$ and was multiform in two cases $(13.33 \%)$; one of them was diagnosed as Lennox-Gastaut syndrome.

EEG findings for all study patients were generalized or multifocal with generalization except in one case where left frontal discharges were found as shown in Table 1.

Brain MRI imaging was normal in 9 cases (60\%). In the other 6 patients (40\%), it revealed mild brain atrophy. In two patients $(13.33 \%)$, there were other findings; one of them showed occipital cyst that couldn't explain the EEG discharges or the semiology of the presented seizures, and the other showed encephalomalacia related to head trauma that occurred during a previous seizure attack with resulting hematoma which was evacuated surgically.

All 15 patients in the current study had drug-resistant epilepsy and underwent microscopic anterior two thirds callosotomy. Three cases (20\%) developed mild and transient (non-significant) complications; one patient developed left sided focal fits in the $2^{\text {nd }}$ postoperative day lasted for seconds and did not recur again; the second patient developed mild left lower limb weakness that was improved within weeks; while the $3^{\text {rd }}$ patient suffered from postoperative behavior changes lasted only for one month.

All study patients were followed at outpatient clinic for clinical outcome for at least 14 months. The patient who underwent surgery at the beginning of the study was followed for more time reaching 36 months.

All study patients had post-operative Brain MRI to assess the extent of callosotomy. They were all good regarding optimal cutting of anterior two thirds of the corpus callosum.

The surgical outcome of the epilepsy was assessed using Engel Surgical outcome.12 cases (80\%) of this study cases had Engel class II improvement of the epilepsy while 3 patients (20\%) had Engel class III improvement. All study cases showed improvement of more than Worth-while improvement.

Only one patient of the less improved ones had a long history of having drug-resistant epilepsy lasting for 20 years. However, there was one patient that suffered for 23 years and his improvement was Engel Class II.

\section{Case Presentation}

In this case presentation, we chose different cases with different patient criteria, different epilepsy semiology and site of discharges in EEGs and different MRI findings. However, they showed good outcome following anterior corpus callosotomy despite this difference.

\subsection{Case Number (1)}

Female patient, 10 years old, with mild subnormal mentality presented with history of recurrent attacks of multiform seizures (including generalized tonic seizures, atonic seizures and automatism) for four years and not well controlled 
with use of multiple anti-epileptic medications which reached up to 5 drugs (Sodium Valproate, Clonazepam, Levetiracetam, Eslicarbazepine and Topiramate) although they were adequate medications and were used inadequate therapeutic doses.

The seizures were gradually increased and became resistant to medical treatment. She had 2 or 3 attacks per day which affected her life.

Pre-operative brain imaging (Figure 2) revealed mild brain atrophy with no other structural brain lesions and on the electroencephalography (EEG), there was bi-frontal epileptic activity.

The patient underwent microscopic anterior corpus callosotomy without any intra-operative or post-operative complications and the patient didn't experience any seizures during the early post-operative time.

Follow up Brain MRI was done after one month to evaluate the extension of the callosotomy as shown in Figure 3.

The patient was followed for 36 months with class II (Engel classification) improvement of the seizures. After 12 months, anti-epileptics withdrawal was started and the patient became using only 2 medications with good epilepsy control.

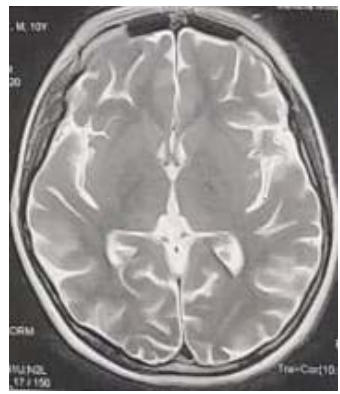

(a)

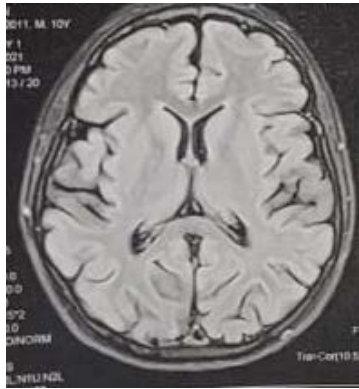

(b)

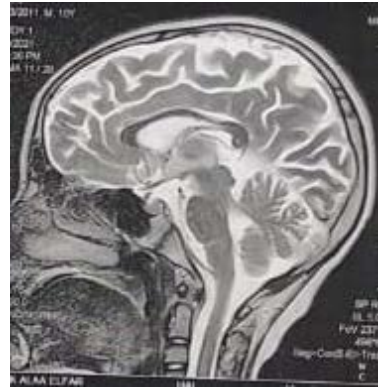

(c)

Figure 2. Brain MRI images. (a) T2axial cut, (b) FLAIR axial cut, (c) T2 mid-sagittal cut which revealed mild brain atrophy with no structural lesions and normal corpus callosum.

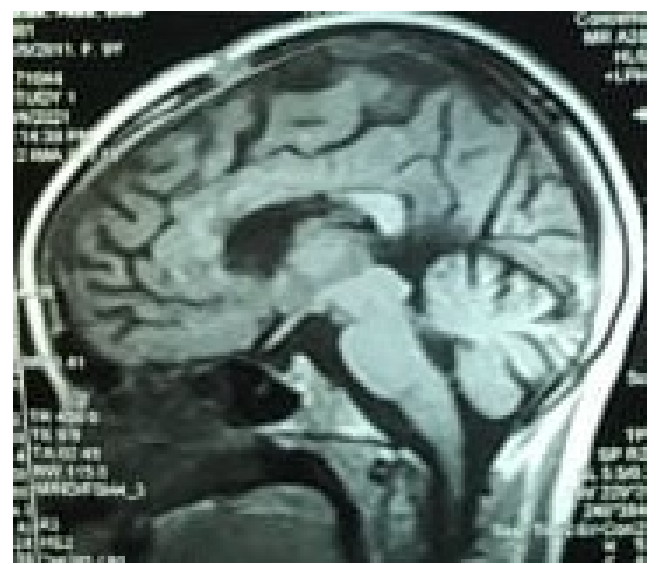

Figure 3. Brain MRI T1 mid-sagittal cut revealing the good extension of the cut of anterior two thirds of the corpus callosum. 


\subsection{Case Number (2)}

Male patient, 29 years old with normal mentality, presented by history of recurrent attacks of generalized tonic-clonic seizures for twenty years and not controlled at all for this long period although using different anti-epileptic medications which were adequate and with adequate doses. Anti-epileptics reached up to 3 medications taken simultaneously (Sodium Valproate, Levetiracetam, and Carbamazepine).

The seizures gradually increased and became resistant to medical treatment. At age of 18, the patient experienced severe seizure attack with falling from height and head trauma which caused intracranial hemorrhage that needed surgical evacuation at other hospitals.

Pre-operative brain imaging (Figure 4) revealed mild brain atrophy with right fronto-parietal encephalomalacia related to previous head trauma and surgical evacuation of intracranial hemorrhage.

The repeated inter-ictal electroencephalographies (EEGs) revealed that there were bilateral fronto-temporal foci of epileptic activity (Figure 5).

The patient underwent microscopic anterior corpus callosotomy without any intra-operative complications. Post-operatively, he suffered from post-operative non-significant transient complication in the form of left sided focal fits lasting for seconds on the $2^{\text {nd }}$ day only.

Follow up Brain CT was done on the second post-operative day to evaluate and search for any cause of the focal fits and evaluate the extension of the callosotomy as in Figure 6.

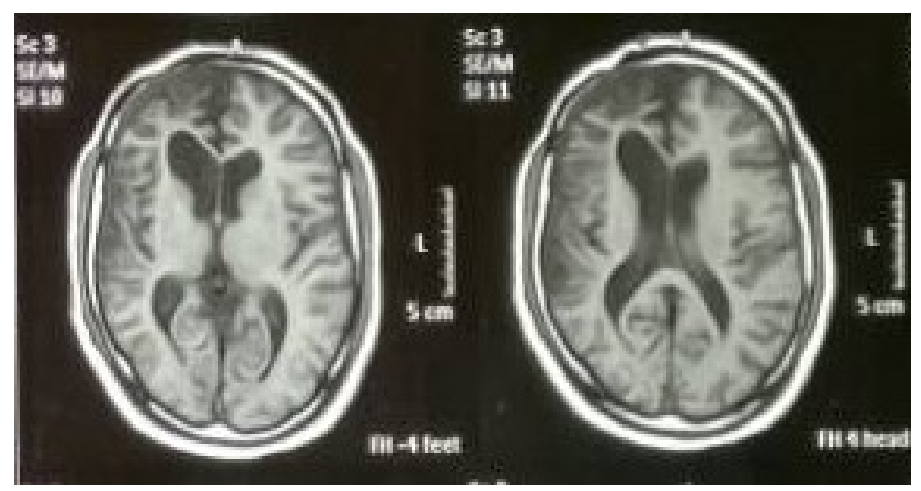

Figure 4. Brain MRI T1 axial cuts showing mild brain atrophy with right fronto-parietal mild encephalomalacia and overlying previous flap of surgery of hemorrhage evacuation.

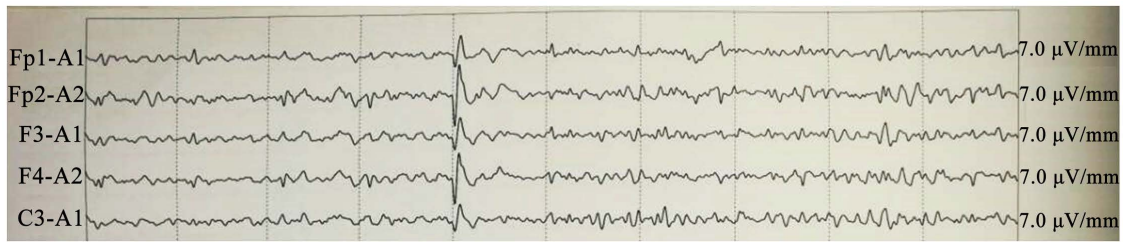

Figure 5. Capture photo taken from the patient EEG revealing bilateral focal fronto-temporal epileptiform activity in the form of spikes and slow waves complexes more on the right side. 

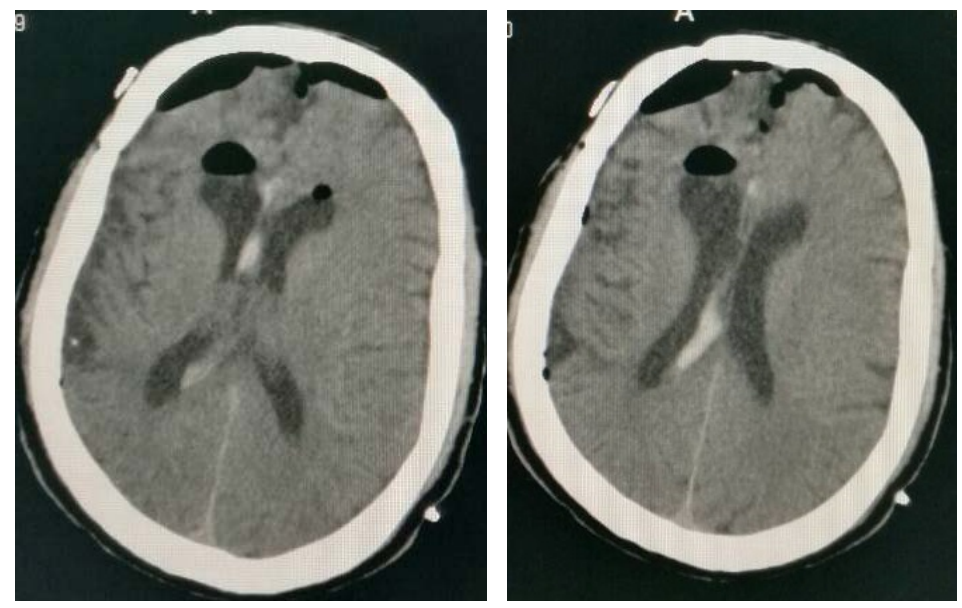

Figure 6. Brain CT axial cuts which revealed expected good extension of cut of corpus callosum and there was minor intra-ventricular bleeding and also minor pneumocephalus.

The patient was followed for 33 months with class III (Engel classification) improvement of the seizures. After 12 months, anti-epileptics withdrawal was started and the patient became on only 2 medications with good epilepsy control.

\subsection{Case Number (3)}

Male patient, 40 years old with normal mentality presented with history of recurrent attacks of generalized toni-clonic seizures for twenty three years and not well controlled during this long period and became resistant to medical treatment during last month with repeated long (for more than 15 minutes) attacks although using different anti-epileptic medications which were adequate and with adequate doses reaching up to 4 medications taken together (Sodium Valproate, Levetiracetam, Phenytoin Sodium and Carbamazepine).

At age of twenty, the patient experienced severe seizure attack with falling from height and head trauma which caused fracture maxilla and fracture foot which needed surgical intervention in another hospital.

Pre-operative brain imaging (Figure 7) revealed no abnormality or any structural lesions. Repeated inter-ictal electroencephalographies (EEGs) revealed left frontal epileptic discharge.

The patient underwent microscopic anterior corpus callosotomy without any intra-operative or post-operative complications. The patient showed good recovery without any seizures during early post-operative period.

Follow up Brain CT was done on the first post-operative day to evaluate the surgery and exclude any surgical complications as in Figure 8.

Follow up Brain MRI was done after one month to evaluate the extension of the callosotomy as shown in Figure 9.

The patient was followed for 29 months with class II (Engel classification) improvement of seizures. After 12 months, Gradual withdrawal of anti-epileptics was started and he continued on 2 drugs with good epilepsy control. 

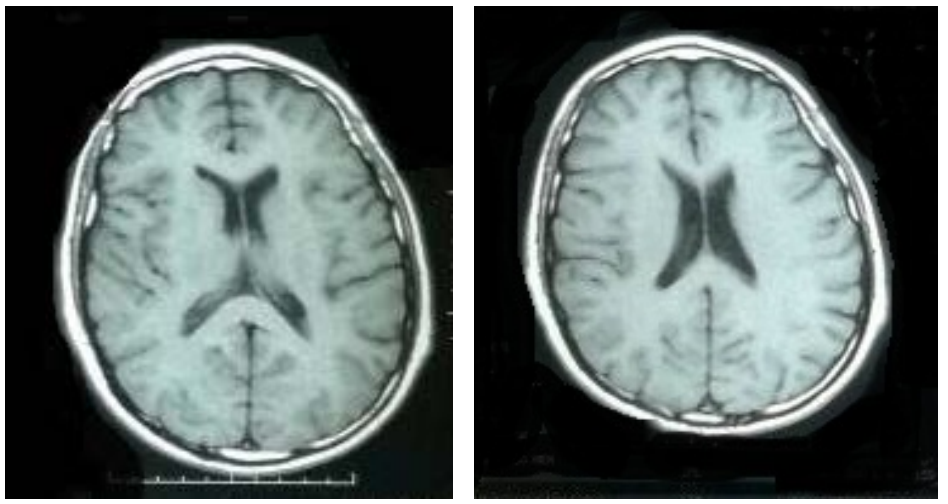

Figure 7. Brain MRI T1 axial cuts revealed no abnormality or structural lesions.
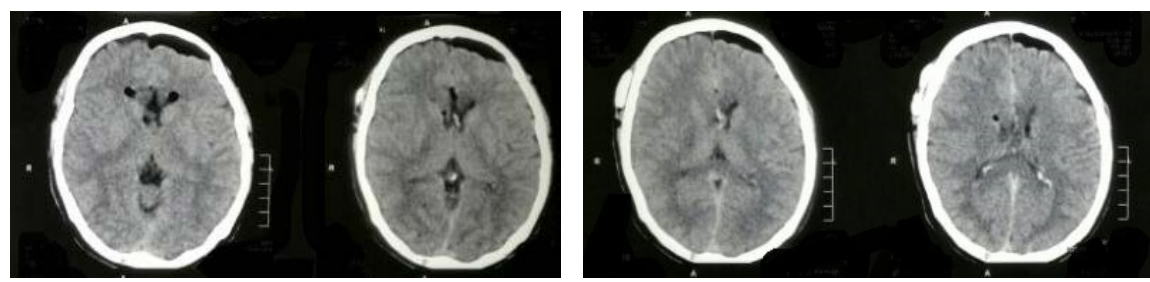

Figure 8. Brain CT axial cuts which revealed the cut of corpus callosum and there was minor intra-ventricular bleeding and also mild pneumocephalus.

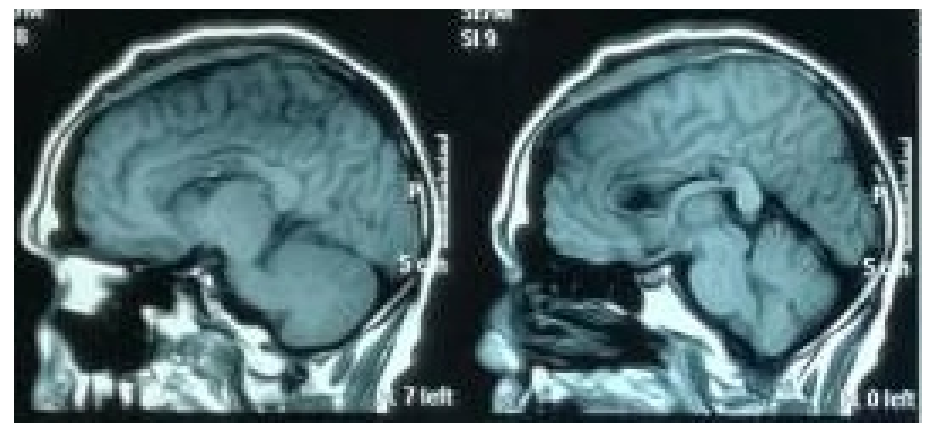

Figure 9. Brain MRI T1 mid-sagittal and parasagittal cuts revealing good extension of cut of the anterior two thirds of corpus callosum.

\section{Discussion}

Epilepsy is a disease that has many complications that may affect the patient's quality of life that may reach SUDEP (Sudden Unexpected Death in Epilepsy). There is about one third of patients showing no control with medical treatment and becoming Drug-Resistant epileptic patients [9].

The prevalence of epilepsy in developing countries is much more than in developed countries (130 - 10 per 1000 in a year respectively) which adds more and more burden to the community. The burden of refractory epilepsy is estimated to be $26 \%$ of neurological disorders burden [9].

Microscopic anterior corpus callosotomy is used as a palliative surgery for cases of medically refractory epilepsy patients with secondary generalization who don't have discrete epileptogenic foci that can be excised [10] [11].

Spencer et al., 1988 [12] showed that complete callosotomy has double the ef- 
fect of anterior callosotomy on surgical outcome of epilepsy control while in series of Sakas et al., 1996 [10] showed that anterior two thirds corpus callosotomy in patients with generalized tonic-clonic seizures had excellent chance of improvement and seizures control (up to $85 \%$ ).

Roberts, 1997 [13] had reported better surgical outcome in patients who underwent complete callosotomy rather than only anterior callosotomy but that study was including patients with different types of seizures.

Graham et al., 2018 [3] reported no significant effect on surgical epilepsy outcome regarding the extent of callosotomy to complete excision.

The current study showed that performing appropriate anterior corpus callosotomy (section of $65 \%$ of the length of the corpus callosum) on appropriately selected patients with drug-resistant generalized tonic clonic epilepsy $(86.67 \%$ of the total study patients) or multiform seizures (13.33\% of the total study patients, one of them was diagnosed as Lennox-Gastaut syndrome), gives the chance of rendering the patients significantly improved in their seizure control with $80 \%$ Engel class II and 20\% Engel class III improvement.

Clinical outcome of the current study is consistent with other studies that recommended anterior two thirds callosotomy in management of generalized tonic-clonic seizures and Lennox-Gastaut syndrome with good outcome and significant reduction of seizures frequency.

Post-operative complications of corpus callosotomy may be resulting from trauma and retraction of the right cerebral hemisphere and draining veins into superior sagittal sinus or from surgical extension of callosotomy. In the literature, these complications are usually mild, transient and of limited frequency. They include contra-lateral hemiparesis, disconnection syndrome and behavior changes [14]. In the series of Sakas et al., 1996 [10]; the frequency of complications was high. The incidence of these complications became much less which may be due to performing microneurosurgical techniques. There were no reported surgical complications in Nguyen et al., 2020 series [15] apart from spontaneously resolving fever.

In the current study; three patients developed mild, non-significant and transient complications. One patient had left sided focal fits on the $2^{\text {nd }}$ post-operative day which lasted for seconds and did not recur again. The $2^{\text {nd }}$ patient had mild left lower limb weakness which improved in few weeks. The $3^{\text {rd }}$ patient suffered from postoperative behavior changes for only one month. Although the frequency of complications was nearly $20 \%$ more than its frequency in other studies, but they were mild and transient.

In the current study, no patient suffered from disconnection syndrome, mostly due to selection of partial rather than complete callosotomy technique in this study. This is consistent with other studies which showed that disconnection syndrome occurs much more in complete callosotomy (12.5\%), while its incidence with anterior callosotomy is $0 \%$ [15].

Sakas et al., 1996 [10] showed that anterior callosotomy in patients with mental retardation had less chance of improvement and poor outcome of seizures 
control (only $50 \%$ of these patients may have chance). However, mental retardation shouldn't be absolute contra-indication for callosotomy.

In the current review; all mentally subnormal patients had good outcome with most of patients' Brain MRI studies revealed mild Brain atrophy.

In the current study, anterior two thirds callosotomy procedure was proved to be a good palliative management of selected patients of medical-resistant epilepsy. It has a very good outcome and rare transient complications. This procedure is cheap and suitable to be done in low economic countries.

Callosotomy is considered an underutilized suitable procedure for management of drug-resistant epilepsy patients, although it is easy and cheap procedure with excellent benefits and rare side effects.

\section{Limitations}

Limitations in this study included different ages of the study patients and different duration of epilepsy which may affect the results. They also included depending only on post-operative imaging for assessment of the extent of callosotomy and lack of use of intra-operative navigation for more accurate assessment of the exact length of callosotomy intra-operatively.

\section{Conclusion}

Anterior corpus callosotomy has excellent outcome and seizure control in generalized tonic-clonic and multiform seizures with bilateral discharges. It is inexpensive procedure which needs no special resources. So, it needs to be prevailed and used more in indicated patients especially in countries with low resources. Disconnection syndrome usually complicates complete callosotomy. So, complete callosotomy is reserved only for cases that need more extension of the excision of corpus callosum.

\section{Conflicts of Interest}

The authors declare no conflicts of interest regarding the publication of this paper.

\section{References}

[1] Téllez-Zenteno, J.F., Dhar, R. and Wiebe, S. (2005) Long-Term Seizure Outcomes Following Epilepsy Surgery: A Systematic Review and Meta-Analysis. Brain, 128, 1188-1198. https://doi.org/10.1093/brain/awh449

[2] Taraschenko, O., Pedavally, S., Samson, K.K., Puccioni, M.J. and Madhavan, D. (2018) Anterior Corpus Callosotomy in Patients with Drug-Resistant Epilepsy: Invasive EEG Findings and Seizure Outcome. Epilepsy \& Behavior Case Reports, 9, 12-18. https://doi.org/10.1016/j.ebcr.2017.12.001

[3] Graham, D., Gill, D., Dale, R.C. and Tisdall, M.M. (2018) Seizure Outcome after Corpus Callosotomy in a Large Paediatric Series. Developmental Medicine \& Child Neurology, 60, 199-206. https://doi.org/10.1111/dmcn.13592

[4] Asadi-Pooya, A.A., Sharan, A., Nei, M. and Sperling, M.R. (2008) Corpus Callo- 
sotomy. Epilepsy \& Behavior, 13, 271-278.

https://doi.org/10.1016/j.yebeh.2008.04.020

[5] Tanriverdi, T., Olivier, A., Poulin, N., Andermann, F. and Dubeau, F. (2009) Long-Term Seizure Outcome after Corpus Callosotomy: A Retrospective Analysis of 95 Patients. Journal of Neurosurgery, 110, 332-342. https://doi.org/10.3171/2008.3.17570

[6] Engel, J., Van Ness, P.C. and Rasmussen, T.B. (1993) With Respect to Epileptic Seizures. In: Engel Jr., J., Ed., Surgical Treatment of the Epilepsies, 2nd Edition, Raven Press Ltd., New York, 609-621.

[7] Graham, D., Tisdall, M.M. and Gill, D. (2016) Corpus Callosotomy Outcomes in Paediatric Patients: A Systematic Review. Epilepsia, 57, 1053-1068.

https://doi.org/10.1111/epi.13408

[8] Cukiert, A., Gross, R.E. and Boulis, N.M. (2018) Technical Aspects of Callosotomy. In: Neurosurgical Operative Atlas: Functional Neurosurgery, 3rd Edition, Thieme Medical Publishers, New York, Chapter 12, 104-107.

[9] Laxer, K.D., Trinka, E., Hirsch, L.J., Cendes, F., Langfitt, J., Delanty, N., Resnick, T. and Benbadis, S.R. (2014) The Consequences of Refractory Epilepsy and Its Treatment. Epilepsy \& Behavior, 37, 59-70. https://doi.org/10.1016/j.yebeh.2014.05.031

[10] Sakas, D.E. and Phillips, J. (1996) Anterior Callosotomy in the Management of Intractable Epileptic Seizures: Significance of the Extent of Resection. Acta Neurochirurgica, 138, 700-707. https://doi.org/10.1007/BF01411475

[11] Baba, H., Toda, K., Ono, T., Honda, R. and Baba, S. (2018) Surgical and Developmental Outcomes of Corpus Callosotomy for West Syndrome in Patients without MRI Lesions. Epilepsia, 59, 2231-2239. https://doi.org/10.1111/epi.14594

[12] Spencer, S.S., Spencer, D.D., Williamson, P.D., Sass, K.J., Novelly, R.A. and Matson, R.H. (1988) Corpus Callosotomy for Epilepsy. I: Seizure Effects. Neurology, 38, 19-24. https://doi.org/10.1212/WNL.38.1.19

[13] Roberts, D.W. (1997) Corpus Callosotomy. In: Engel, J.J. and Pedley, T.A., Eds., Epilepsy: A Comprehensive Textbook, Lippincott-Raven Publishers, Philadelphia, 1851-1858.

[14] Geoffroy, G., Lassonde, M., Delisle, F. and Decarie, M. (1983) Corpus Callosotomy for Control of Intractable Epilepsy in Children. Neurology, 33, 891-897. https://doi.org/10.1212/WNL.33.7.891

[15] Lien, N.D., Tuan, D.A., Hung, C.V., Lepard, J.R. and Rocque, B.G. (2020) Corpus Callosotomy for Treatment of Drug-Resistant Epilepsy: A Review of 16 Pediatric Cases in Northern Vietnam. Journal of Neurosurgery Pediatrics, 25, 582-587. https://doi.org/10.3171/2019.12.PEDS19638 